\title{
3-dimensional composite scaffolds consisting of apatite-PLGA-atelocollagen for bone tissue engineering
}

\author{
Masaaki TAKECHI ${ }^{1}$, Koji OHTA ${ }^{1}$, Yoshiaki NINOMIYA ${ }^{1}$, Misato TADA ${ }^{1}$, Masayuki MINAMI ${ }^{1}$, Megumi TAKAMOTO ${ }^{1}$, \\ Akira OHTA ${ }^{1}$, Takayuki NAKAGAWA ${ }^{1}$, Akiko FUKUI' ${ }^{1}$, Youji MIYAMOTO ${ }^{2}$ and Nobuyuki KAMATA ${ }^{1}$ \\ ${ }^{1}$ Department of Oral and Maxillofacial Surgery, Graduate School of Biomedical and Health Sciences, Hiroshima University, 1-2-3 Minamiku, Kasumi, \\ Hiroshima 734-8553, Japan \\ ${ }^{2}$ Department of Oral Surgery, Subdivision of Molecular Oral Medicine, Division of Integrated Sciences of Translational Research, Institute of Health \\ Biosciences, The University of Tokushima Graduate School, 3-18-15 Kuramoto, Tokushima, 770-8503, Japan \\ Corresponding author, Masaaki TAKECHI; E-mail: takechi@hiroshima-u.ac.jp
}

\begin{abstract}
We fabricated 3-dimensional scaffolds consisting of biodegradable poly(D, L-lactide-co-glycolic acid)(PLGA)(75/25) with hydroxyapatite particles containing atelocollagen (aAC). The aim of this study was to evaluate this new type of scaffold in regard to its basic properties and biocompatibility. Characterization of the obtained scaffolds was performed to know the porosity, shrinkage, diametral tensile strength, and biocompatibility. Composite scaffolds made of PLGA with hydroxyapatite particles containing atelocollagen (PL-aAC) showed a greater strength and stability than PLGA scaffolds. PL-aAC also exhibited superior performance in terms of cell attachment and proliferation as compared to PLGA, while histological findings showed that PL-aAC had an excellent response toward soft tissues. Our results strongly suggest that PL-aAC is more useful for cell transplantation as compared to PLGA for bone tissue engineering.
\end{abstract}

Keywords: PLGA, Apatite, Atelocollagen, Scaffold, Bone tissue engineering

\section{INTRODUCTION}

Recently, poly(D,L-lactic-co-glycolic acid)(PLGA) has been investigated as a scaffold material for applications in bone tissue engineering. Although PLGA is biodegradable and hydrophobic, porous scaffolds fabricated with PLGA float in cell culture medium, while they also have limited ability to promote cell attachment and proliferation ${ }^{1}$. Moreover, it was reported that PLGA scaffolds induced a slight inflammatory response after implantation in vivo ${ }^{2}$. To improve these drawbacks of PLGA only, we fabricated 3-dimensional (3D) scaffolds consisting of PLGA with apatite cement (AC) particles containing atelocollagen for use as scaffolds in bone tissue engineering.

$\mathrm{AC}$ is a bioactive cement that transforms to hydroxyapatite (HAp) when exposed to moisture ${ }^{3)}$. Various types of AC have been developed, in attempts to improve the properties of $\mathrm{AC}^{4,5}$. In the previous study, we fabricated $\mathrm{AC}$ containing atelocollagen $(\mathrm{aAC})$ and evaluated its feasibility in vivo ${ }^{6}$. As a result, it was found aAC showed an excellent tissue response when aAC was implanted subcutaneously in rats. Notably, collagen accelerates cell attachment, proliferation, and osteoconduction when used as a coating material on calcium phosphate ceramics, such as HAp and tricalcium phosphate. Furthermore, collagen, a primary component of the organic substrate comprising bone, is known to play important roles in the formation and mechanical properties of bone. Based on its physical and biological properties, it is often used in preparation of resorbable biomaterials ${ }^{7}$. Although an immunogenic reaction is a serious problem when collagen is applied in biomaterials, atelocollagen is more preferable for biomaterial use as compared to other kinds, because it has the lowest level of antigenicity ${ }^{6}$.

In the present study, we developed PLGA with aAC composite scaffolds (PL-aAC) using a solvent casting/ particulate leaching method. The objective of our investigation was to fabricate novel $3 \mathrm{D}$ scaffolds and evaluate their biocompatibility, mechanical strength, shrinkage, and ability to promote cell attachment and proliferation.

\section{MATERIALS AND METHODS}

\section{Materials}

Poly(D,L-lactide-co-glycolic acid)(PLGA)(75/25); corefront corporation, Tokyo, Japan) produced with a copolymer mass ratio of 75:25 from lactide and glycolide using stannous octoae as the initiator, and an inherent viscosity of $0.68 \mathrm{dL} / \mathrm{g}$ at $-10^{\circ} \mathrm{C}$ in $\mathrm{CHCl}_{3}$, was prepared. The other materials used in this study were tetracalcium phosphate (TTCP; Taihei Chemical Industrial Co., Osaka, Japan ), dicalcium phosphate anhydrous (DCPA; J.T, Baker, N.J., USA) and dimethyl sulfoxide (DMSO; Sigma Chemical Company, MO, USA). Sugar particles (Mitsui Sugar Co., Ltd, Tokyo, Japan) were passed through a $1 \mathrm{~mm}$ sieve.

\section{Preparation of aAC powder}

The powder phase of AC was prepared as previously described $^{8)}$. In brief, an equimolar mixture of TTCP and DCPA was mixed using a speed mill (SK-M2, Kyoritsuriko, Tokyo, Japan), then sterilized by exposure to $20 \mathrm{kGy}$ of gamma radiation and kept in a vacuum 
desiccator set at $60^{\circ} \mathrm{C}$ until use. For the preparation of aAC, 2\% atelocollagen gel (KOKEN Co., Ltd, Tokyo, Japan) was used as the liquid phase ${ }^{9}$. The powder and liquid phases were mixed at a $\mathrm{P} / \mathrm{L}$ ratio of 2.0 , then the obtained paste was allowed to harden at room temperature for $24 \mathrm{~h}$. Thereafter, it was crushed into powder and passed through a $100 \mu \mathrm{m}$ sieve. The atelocollagen content of aAC (1 g) was $0.1 \mathrm{mg}$. The resultant powder was poured and mixed with PLGA solution as follows.

\section{Preparation of PL-aAC composite scaffold}

PL-aAC composite scaffolds were fabricated using the solvent casting/particulate leaching method ${ }^{10)}$. In brief, PLGA(75/25) was dissolved in DMSO according to the concentration of $10 \%(\mathrm{w} / \mathrm{w})$. PLGA solution was mixed with sugar granules and aAC powder at a PLGA:aAC of $1: 1$ [PL-aAC(1)] and 1:2 [PL-aAC(2)]. At the same time, a PLGA solution with no aAC was mixed with sugar granules of $1 \mathrm{~mm}$ [PL]. Then, all of the dispersion was cast into a mold and frozen immediately at $-18^{\circ} \mathrm{C}$. The frozen sample was soaked into deionized distilled water $\left(\mathrm{ddH}_{2} \mathrm{O}\right)$ and the sugar granules were leached out of the PLGA-aAC mixture. Subsequently, the produced scaffolds were dried for 2 days. In this manner, $3.0 \times 3.0 \times 5.0 \mathrm{~cm}$ scaffolds were produced. The samples were cut into cubes for each test. After sectioning, the atelocollagen content of PL-aAC(1) and PL-aAC(2) was $1.10 \times 10^{-3}$ and $2.19 \times 10^{-3} \mathrm{mg}$, respectively.

\section{Scanning electron microscopy (SEM)}

The surface and cross-sectional morphologies of porous PLGA and PL-aAC were observed using a scanning electron microscope (SEM, JSM-5300, JEOL, Tokyo, Japan) at an acceleration voltage of $15 \mathrm{kV}$. After incubation, cell seeded scaffolds were quickly rinsed with $0.1 \mathrm{~mol} \cdot \mathrm{L}^{-1}$ cacodylate buffer 2 times, then fixed in Karnorvsky's fixative at room temperature and placed into a $4^{\circ} \mathrm{C}$ bath for no less than $2 \mathrm{~h}$. Next, they were dehydrated through a graded ethanol series, critical point dried with liquid $\mathrm{CO}_{2}$, and sputter-coated with 10 $\mathrm{nm}$ of gold under a vacuum condition.

\section{Pore size and porosity analysis}

The mean pore diameter was evaluated using the SEM images of cell-free scaffolds. Linear measurements from the most distant points of the pore openings were

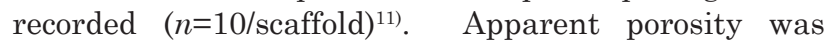
determined using a method similar to that reported by Xinhua et al. ${ }^{12)}$. Briefly, a cube sample $(5 \times 5 \times 7 \mathrm{~mm})$ was cut out of a scaffold sample, then the volume was calculated from the measured dimensions, and the mass was determined with an analytical balance. Five samples of each scaffold were measured to calculate average density. Apparent porosity was calculated from the scaffold density (P) and the polymer skeletal density $\left(\mathrm{P}_{0}\right)$ using the following equation:

Porosity $(\%)=\left(1-\mathrm{P} / \mathrm{P}_{0}\right) \times 100$

\section{$X$-ray diffraction (XRD) analysis}

The compositional change in PL-aAC upon setting or gamma irradiation was analyzed using powder X-ray diffraction (XRD; Rint 2000, Rigaku, Tokyo, Japan). Measurements were performed with a vertically mounted diffractometer system with $\mathrm{Ni}$ filtered $\mathrm{CuK} \alpha$ radiation $(0.154 \mathrm{~nm})$ generated at $30 \mathrm{kV}$ and $16 \mathrm{~mA}$. The samples were scanned from 3 to $60^{\circ}$ in $2 \theta$ (where $\theta$ is the Bragg angle) to determine the reaction product in continuous mode.

\section{Mechanical strength measurement}

The mechanical strength of PLGA and PL-aAC was evaluated in terms of diametral tensile strength (DTS). The column shaped samples were cut at a diameter of 8.5 $\mathrm{mm}$ and height of $10 \mathrm{~mm}$. Testing was performed under four conditions: dry, and wet $/ 37^{\circ} \mathrm{C} / 2$ weeks, 4 weeks, and 8 weeks. The samples were crushed at a cross-head speed of $1 \mathrm{~mm} \mathrm{~min}{ }^{-1}$ using a universal testing machine (AGS-500A, Shimadzu, Kyoto, Japan).

\section{Shrinkage test}

The samples were cut into $5 \times 5 \times 7 \mathrm{~mm}$ cubes for the shrinkage test. The mass of each scaffold was measured before and after incubation in $\alpha$-MEM at $37^{\circ} \mathrm{C}$ for 2,4 and 8 weeks, respectively. The \% decrease in mass was calculated from the following equation ${ }^{13)}$.

$$
\text { Mass loss }(\%)=100 \times\left(\mathrm{M}_{0} / \mathrm{M}_{\mathrm{t}}\right) / \mathrm{M}_{0}
$$

Where $\mathrm{M}$ with subscript 0 and $\mathrm{t}$ indicates the mass at the immersion time of 0 and $t$, respectively. All values are presented as averages of the samples.

\section{Initial cell attachment and proliferation of MC3T3-E1 cells}

In this study, MC3T3-E1 cells were used. The culture medium was $\alpha$-MEM (Dainihonseiyaku, Osaka, Japan) supplemented with $10 \%$ fetal bovine serum (Whittaker Bioproducts Inc., Walkerville, MO, USA). Each scaffold was placed in each well of a 48-well plate (Corning, NY, USA). The prepared porous scaffolds were cut into $5 \times 5 \times 7 \mathrm{~mm}$ cubes and prewetted in phosphate-buffered saline (PBS) for $2 \mathrm{~h}$. MC3T3-E1 cells $\left(1 \times 10^{4}\right)$ were resuspended in $100 \mu \mathrm{L}$ of media, then the concentrated cell suspensions were pipetted onto scaffolds and incubated in an atmosphere containing $5 \% \mathrm{CO}_{2}$ at $37^{\circ} \mathrm{C}$. After $2 \mathrm{~h}, 1 \mathrm{~mL}$ of medium was added to the 48 -well plate (Corning) and the medium was changed every 3 days. After culturing for $5 \mathrm{~h}, 1$ week, and 2 weeks, the number of cells was counted.

\section{Histological preparations}

For the animal experiments, the housing care and experimental protocol were approved by the Animal Care and Use Committee of the University of Tokushima School of Dentistry. Eight-week-old male Wister rats were obtained commercially (Charles River Laboratories, Inc, Wilmington, MA, USA) and fed standard pellets and water freely, then used for a biocompatibility study of 


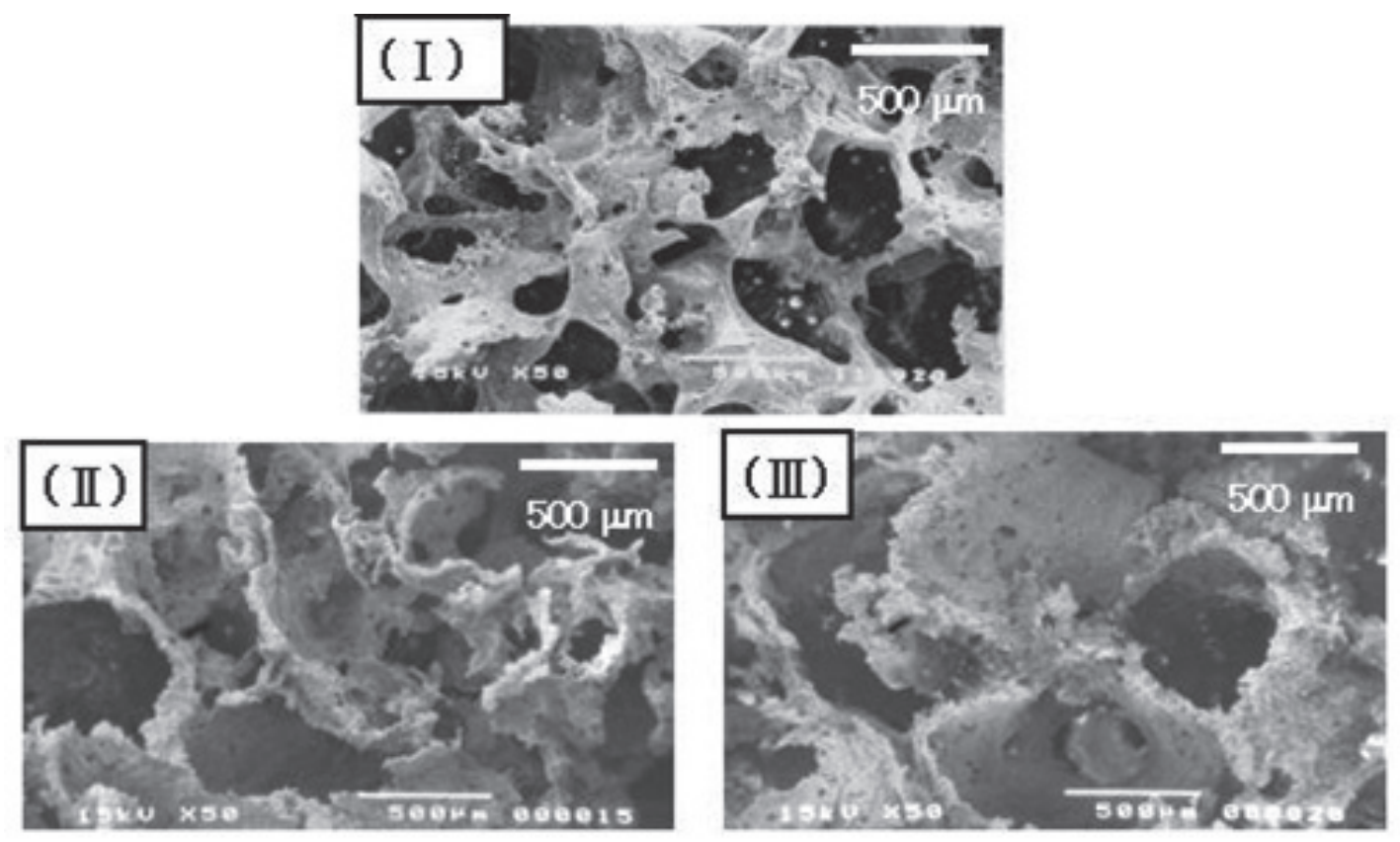

Fig. 1 SEM images of (I) PLGA, (II) PL-aAC(1), and (III) PL-aAC(2) (Scale bars=500 $\mu \mathrm{m}$ ).

the scaffolds without cells. PLGA, PL-aAC(1), and PL-aAC(2) samples were cut into $5 \times 5 \times 7 \mathrm{~mm}$ cubes and surgically implanted into subcutaneous tissue in the abdomen of 6 rats. The soft tissues containing scaffolds were removed from 3 rats each at 3 days and 3 weeks after surgery, then fixed in 10\% neutral-buffered formalin and embedded in resin (OsteoResin; Wako). Finally, they were sliced into 5 - $\mu \mathrm{m}$-thick serial longitudinal sections, stained with hematoxylin-eosin, and subjected to light microscopic examination.

\section{RESULTS}

Figure 1 shows SEM images of the surface and crosssectional morphologies of porous (I)PLGA, (II)PL-aAC(1), and (III)PL-aAC(2). PLGA and PL-aAC had the highly interconnected macroporous structure of representative scaffold. When more aAC particles were added, the small pores decreased, and consequently, the level of interconnection decreased. Figure 2 shows the pore size and porosity of a representative scaffold. The line graph indicates the porosity, and the bar graph shows the pore size. There were no significant difference among PLGA, PL-aAC(1), and PL-aAC(2). Figure 3 presents comparisons of XRD patterns for PLGA, PL-aAC(1), and PL-aAC(2) with those for the powder phase of PLGA and aAC. The peaks assigned to HAp $\left(25.9^{\circ}\right.$ and $31.8^{\circ}$ in $\left.2 \theta\right)$ were detected in PL-aAC(1) and PL-aAC(2). The mechanical strength of each scaffold is shown in Fig. 4. The DTS of PLGA was significantly lower as compared with that of PL-aAC(1) and PL-aAC(2) under all testing conditions, while higher aAC ratios produced better mechanical properties under all conditions. Figure 5 shows the shrinkage test of PL-aAC(2), PL-aAC(1), and

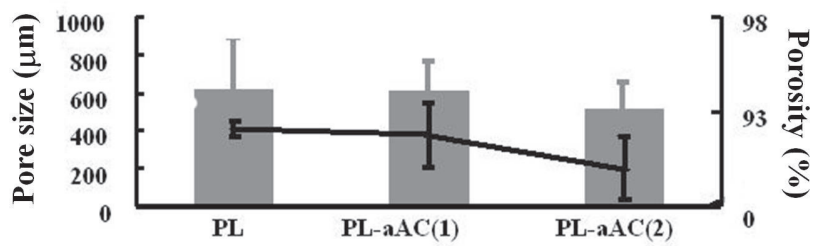

Fig. 2 Pore size and porosity of the scaffolds. SEM images of cell-free scaffolds were evaluated to determine the mean pore diameter. Linear measurements from the most distant points of pore openings were recorded ( $n=10 /$ scaffold). Descriptive statistics were calculated and comparisons of the mean pore diameters among the scaffolds were evaluated using analysis of variance $(\alpha=0.01)$.

PLGA before and after incubation in $\alpha$-MEM for 2, 4 and 8 weeks, respectively. As a result, the mass reduction of PLGA was larger than of PL-aAC(1) and PL-aAC(2) at the same time periods, while the addition of aAC particles to the scaffolds resulted in a significant mass reduction. Figure 6 shows the initial attachment and proliferation of MC3T3-E1 cells on scaffolds. The initial attachment and proliferation of MC3T3-E1 cells to PL-aAC(1) and PL-aAC(2) were significantly greater than with PLGA. Specifically, the number of cells proliferating in PL-aAC(1) and PL-aAC(2) was significantly increased as compared to that in PLGA at 2 weeks. Addition of aAC particles to the scaffolds resulted in a significant increase in initial cell attachment and proliferation. Figure 7 


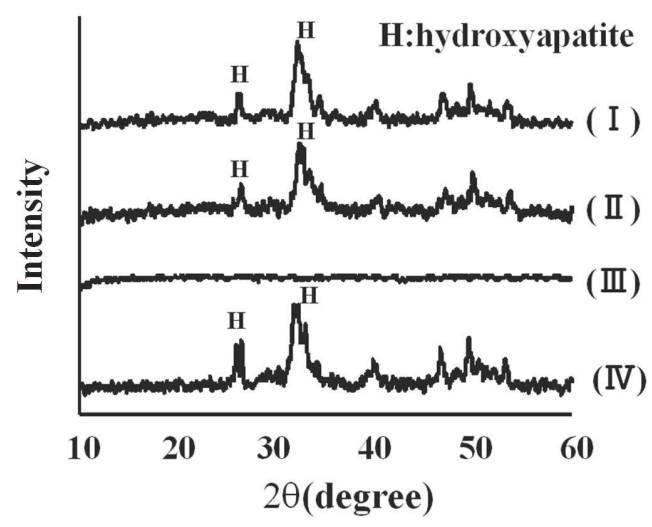

Fig. 3 Powder X-ray diffraction patterns of (I) PL-aAC(2), (II) PL-aAC(1), (III) PLGA, and (IV) aAC. The powder phase of calcium phosphate cement and poorly crystallized aAC are shown for comparison.

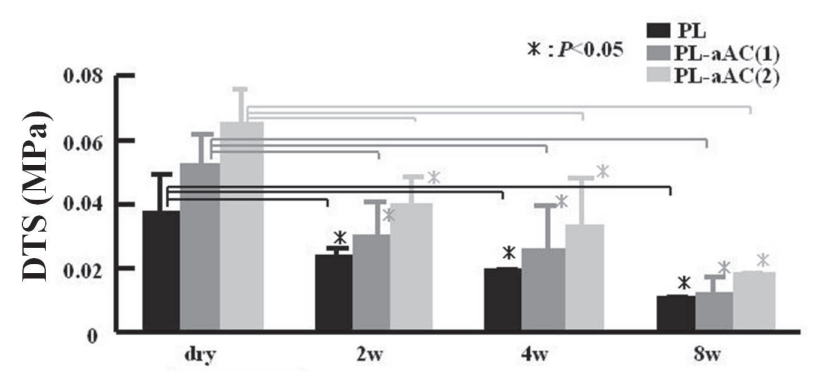

Fig. 4 DTS value of PLGA, PL-aAC(1), and PL-aAC(2) under three conditions: dry, wet $/ 37^{\circ} \mathrm{C} / 1$ week and 2 weeks.

shows SEM images of MC3T3-E1 cells cultured for 2 weeks on PLGA, PL-aAC(1), and PL-aAC(2). The shape of the cells expanded on the surface was nearly the same with all of the scaffolds. Figure 8 summarizes the histological appearances of soft tissues associated with PLGA and PL-aAC(2). PL-aAC(2) at 3 days after implantation showed slight inflammation consisting of a smaller number of lymphocytes, plasma cells, and macrophages as compared to PLGA. On the other hand, the inflammatory response of tissues associated with PL-aAC(2) was resolved after 3 weeks. These results indicate that addition of aAC to PLGA resulted in an excellent response in associated soft tissues as compared with PLGA alone.

\section{DISCUSSION}

Scaffolds play an essential role in supporting bone regeneration, as their $3 \mathrm{D}$ structure provides physical support and acts as a substrate to regulate cell growth, adhesion, and differentiation ${ }^{14}$. However, they also have some disadvantages. The degradation products reduce the local $\mathrm{pH}$ value, which in turn, may accelerate the

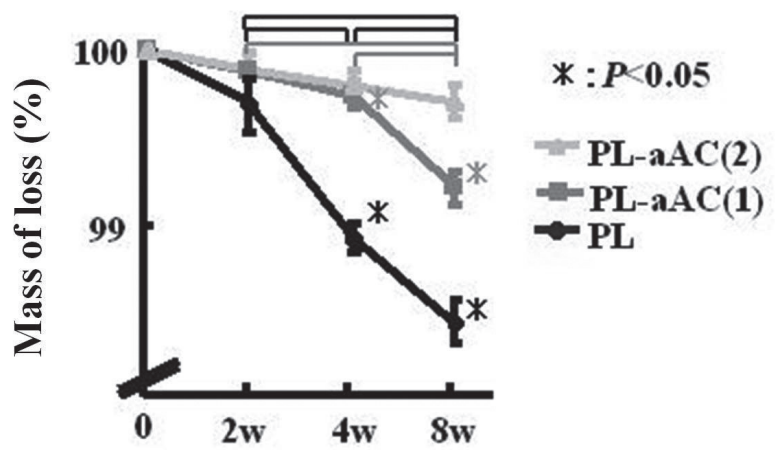

Fig. 5 Shrinkage test results with PL-aAC(2), PL-aAC(1), and PLGA before and after incubation in $\alpha$-MEM. The results are shown as the mean \pm standard deviation $(n=5) . \quad *$ and bars indicate significant difference as compared with PLGA and others, respectively.

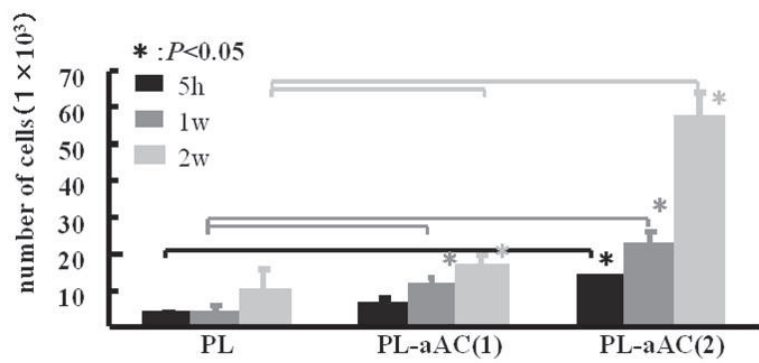

Fig. 6 Initial attachment and proliferation of MC3T3-E1 cells on scaffolds. The numbers of MC3T3-E1 cells on scaffolds were determined after $5 \mathrm{~h}, 1$ and 2 weeks of culturing. The results are shown as the mean \pm standard deviation $(n=5) . \quad *$ and bars indicate a significant difference as compared with PLGA and others, respectively.

polyester degradation rate and induce an inflammatory reaction. In addition, the mechanical properties of PLGA are relatively low, which limits its use in bone tissue regeneration, especially at the in vivo implant site ${ }^{15}$. Also, PLGA has a low level of surface wettability due to its composition of non-charged elements. Such hydrophobic surfaces are unfavorable to osteogenic cells, as they show a lower proliferative and higher apoptotic rate on hydrophobic surfaces as compared to hydrophilic surfaces ${ }^{15,16)}$. Finally, PLGA has a bioinert surface that lacks bioactive functions for bone formation, therefore evoking minimal tissue responses ${ }^{17}$.

HAp has been investigated as a bone replacement material since it mimics natural bone mineral and development of biodegradable polymer/bioceramic composites could be a solution to the problems noted above. The incorporation of synthetic HAp into PLGA is expected to result in a promising composite scaffold for bone tissue engineering, as improved hydrophilic and 



Fig. 7 SEM images of MC3T3-E1 cells cultured for 2 weeks on (I) PLGA, (II) PL-aAC(1), and (III) PL-aAC(2) (Scale bars=10 $\mu \mathrm{m})$.
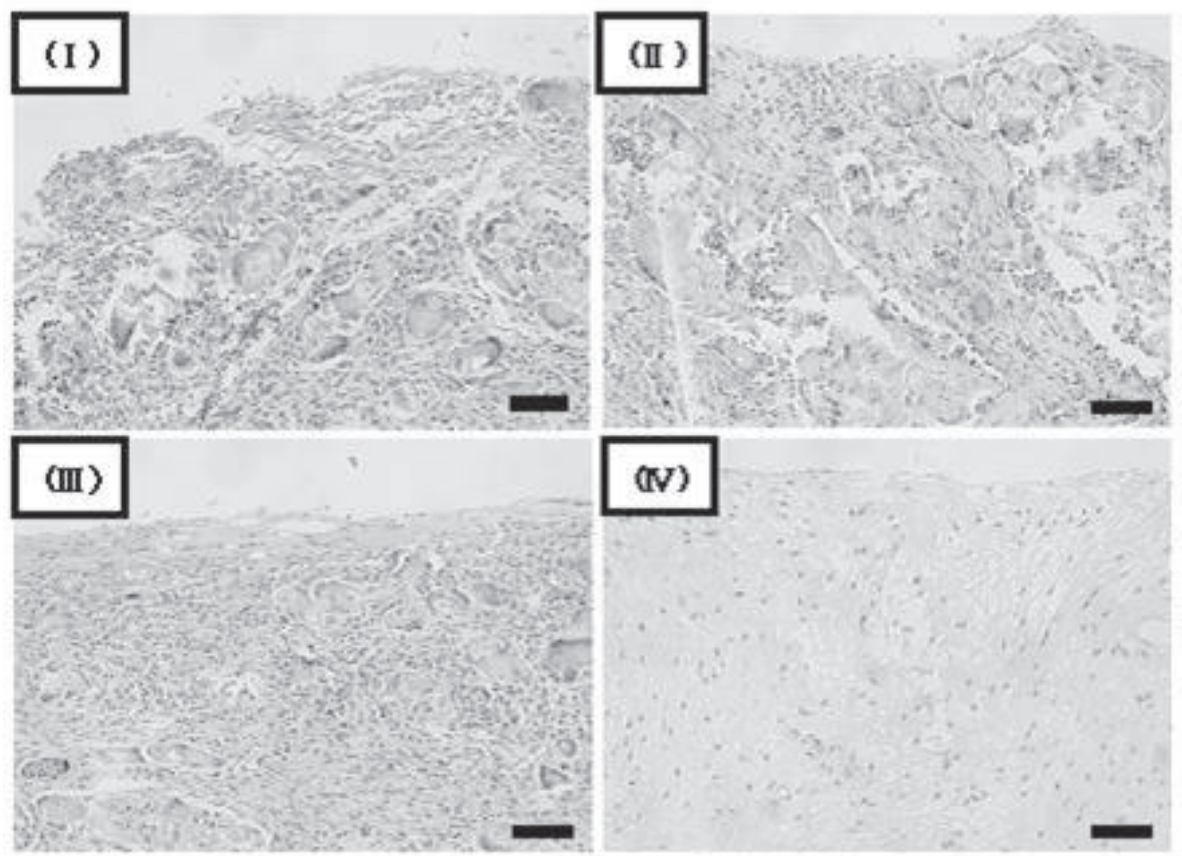

Fig. 8 Photomicrographs of subcutaneous tissue surrounding (I) PLGA and (II) PL-aAC(2) scaffolds at 3 days after surgery, and (III) PLGA and (IV) PL-aAC(2) 3 weeks after surgery. (hematoxylin-eosin stain) (Scale bars $=250 \mu \mathrm{m}$ ).

osteoconductive properties may be provided by HAp, while the acidic degradation byproducts from PLGA may be buffered, resulting in better mechanical properties ${ }^{18,19}$.

In the present study, we used the solvent casting/ particulate leaching method to fabricate highly porous PL-aAC composite scaffolds, which resulted in a highly interconnected macroporous structure. XRD patterns in PL-aAC confirmed the presence of aAC regardless of the presence or absence of PLGA. Also, PLGA acted as a matrix and aAC particles acted as fillers in the PLGA network. Therefore, it was confirmed that a higher PL-aAC ratio did produce superior mechanical properties. 
Scaffolds used for bone tissue engineering should maintain their structural integrity during cell culture. However, it was reported that PLGA undergoes bulk degradation by simple hydrolysis into lactic and glycolic $\operatorname{acids}^{20)}$. Moreover, the acidic degradation products reduced the local $\mathrm{pH}$ and accelerated the degradation rate $^{21)}$. It was also reported that the $\mathrm{pH}$ of PLGA/HAp composite is more stable than that of PLGA and HAp scaffolds ${ }^{13)}$. In the present study, PL-aAC showed a decreased level of acidic degradation by products from PLGA during incubation, and maintained its structure and pores for new bone formation, thus the shrinkage of PL-aAC was superior to that of PLGA. Cell attachment and proliferation are affected by the hydrophilic property, structure, and chemical composition of the scaffold surface. Also, the amount of cell adhesive proteins in aAC, such as fibronectin and vibronectin, subsequently dictate cell adhesion behavior ${ }^{22,23)}$, because most cells attach to appropriately modified surfaces far better than to hydrophobic surfaces, including those with fewer proteins ${ }^{24-28)}$. Moreover, collagen, specifically type I, enhances the adhesion and proliferation of cells, which is due to specific interactions with adhesion proteins ${ }^{6,7}$. These findings could be attributed to the effect of increased initial cell attachment of PL-aAC as compared with PL, thereby increasing cell proliferation. Our results demonstrated that PL-aAC had an excellent initial response toward soft tissues as compared with PLGA. The latter crumbled in the initial stage, because it did not have sufficient mechanical strength to resist the pressure ${ }^{27)}$. In addition, PLGA degraded to acidic products and caused $\mathrm{pH}$ changes, which resulted in crumbling scaffolds and acidic products of PLGA lead to inflammation in vivo ${ }^{8}$.

Based on these results, the PL-aAC scaffolds may be suitable for the implant-type tissue-engineered bone. Also, the ideal absorption of biodegradable polymers should be synchronized with the bone regeneration. In future, we need further experiments to establish the ideal scaffolds by optimization of the biodegradability in the polymers. Additionally, we should accumulate the knowledge and experience of postoperative timedependent changes for the 3D shapes of the tissueengineered bone, not only in the immunocompromised animals, such as nude mice, but also in the rodents or the large-sized animals with normal immune systems.

\section{CONCLUSION}

The present results indicate that PL-aAC could be a better scaffold than PLGA for bone tissue engineering. Nevertheless, further in vivo evaluations are needed to test its ability to enhance new bone formation as identified in this preliminary investigation.

\section{ACKNOWLEDGMENTS}

This investigation was supported by the Department of Oral and Maxillofacial Surgery, Institute of Health Biosciences, The University of Tokushima Graduate
School, by a Grant-in-Aid for Scientific Research from the Ministry of Education, Science and culture, Japan, and by a Health Science Research Grant from the Ministry of Health and Welfare, Japan.

\section{REFERENCES}

1) Se HO, Soung GK, Eun SK, Sang HC, Jin HL. Fabrication and characterization of hydrophilic poly(lactic-co-glycolic acid)/poly(vinyl alcohol) blend cell scaffolds by melt-molding particulate-leaching method. Biomaterials 2003; 24: 4011-4021.

2) Martin R, Matthias WL, Dominik J, Carlos C, Alexander S, Rolf M, NilsClaudius G, Michael DM. Angiogenic and inflammatory response to biodegradable scaffolds in dorsal skinfold chambers of mice. Biomaterials 2006; 27: 5027-5038.

3) Chow LC, Takagi S, Scheetz BE, Landers AG, Odler I, Jennings H. In specialty cements with advanced properties. Materials Research Society, Pittsburgh, 1989; PA179: 3.

4) Miyamoto $Y$, Ishikawa K, Takechi M, Yuasa M, Kon M, Nagayama M, Asaoka K. Non-decay type fast-setting calcium phosphate cement: setting behaviour in calf serum and its tissue response. Biomaterials 1996; 17: 1429-1435.

5) Miyamoto Y, Ishikawa K, Takechi M, Takemoto T, Yoshida Y, Nagayama M, Kon M, Asaoka K. Tissue response to fast-setting calcium phosphate cement in bone. J Biomed Mater Res 1997; 37: 457-464.

6) Takechi M, Miyamoto Y, Ishikawa K, Momota Y, Yuasa T, Tatehara S, Takano H, Minamiguchi S, Nagayama M. Histological evaluation of apatite cement containing atelocollagen. Dent Mater J 2007; 26: 194-200.

7) Forest PO, Karoum R, Gagnieu CH. Influence of gradual introduction of hydrpphobic groups(stearic acid) in denatured atelocollagen on fibroblasts behavior in vitro. J Biomed Mater Res A 2006; 80: 758-767.

8) Ishikawa K, Takagi S, Chow LC, Ishikawa Y, Eanes ED, Asaoka K. Behavior of a calcium phosphate cement in simulated blood plasma in vitro. Dent Mater J 1994; 10: 26-32.

9) Takechi M, Miyamoto Y, Ishikawa K, Yuasa M, Nagayama M, Kon M, Asaoka K. Non-decay type fast-setting calcium phosphate cement using chitosan. J Mater Sci: Mater Med 1996; 7: 317-322.

10) Guan L, Davies JE. Preparation and characterization of a highly macroporous biodegradable composite tissue engineering scaffold. J Biomed Mater Res A 2004; 71: 480-487.

11) Kacey GM, Jeffery WS, Prashant NK, Paul AD, Lee EW. In vitro analysis of biodegradable polymerblend/hydroxyapatite composites for bone tissue engineering. J Biomed Mater Res 1999; 47: 324-335.

12) Xinhua Z, Shaofeng R, Kwang-Sok K, Dufei F, Benjamin SH, Benjamin C. Structure and morphology changes during in vitro degradation of electrospun poly(glycolide-co-lactide) nanofiber membrane. Biomacromolecules 2003; 4: 416-423.

13) Ara M, Watanabe M, Imai Y. Effect of blending calcium compounds on hydrolytic degradation of poly(DL-lactic acidco-glycolic acid). Biomaterials 2002; 23: 2479-2483.

14) Wolfgang L, Fabian P, Wolfgang L, Karsten S, Arndt FS, Michael A, Johannes MR, Matthias E. Biologically and chemically optimized composites of carbonated apatite and polyglycolide as bone substitution materials. J Biomed Mater Res 2001; 54: 162-171.

15) Ruiyun Z, Peter XM. Poly( $\alpha$-hydroxyl acids)/hydroxyapatite porous composites for bone-tissue engineering. I. Preparation and morphology. J Biomed Mater Res 1999; 44: 446-455.

16) Anselme K. Osteoblast adhesion on biomaterials. Biomaterials 2000; 21: 667-681.

17) Howe AK, Aplin AE, Juliano RL. Anchorage-dependent ERK 
signaling-mechanisms and consequences. Curr Opin Genet Dev 2002; 12: 30-35.

18) Lu HH, El-amin SF, Scott KD, Laurencin CT. Threedimensional, bioactive, biodegradable, polymer-bioactive glass composite scaffolds with improved mechanical properties support collagen synthesis and mechanical properties support collagen synthesis and mineralization of human osteoblast-like cells in vitro. J Biomed Mater Res A 2003; 64: 465-474.

19) Jung Y, Kim YH, Kim SH, Kim BS, Kim S,Choi CY, Kim H. A poly(lactic acid)/calcium metaphosphata composite for bone tissue engineering. Biomaterials 2005; 26: 6314-6322.

20) Jeffrey MK, Molly SS, Davies JE. Bone formation on twodimensional poly(DL-lactide-co-glycolide)(PLGA) films and three-dimensional PLGA tissue engineering scaffolds in vitro. J Biomed Mater Res A 2003; 64: 388-396.

21) Xinhua Z, Shaofeng R, Kwang-Sok K, Dufei F, Benjamin SH, Benjamin C. Structure and morphology changes during in vitro degradation of electrospun poly(glycolide-co-lactide) nanofiber membrane. Biomacromolecules 2003; 4: 416-423.

22) Aframian DJ, Cukierman E, Nikolovski J, Mooney DJ, Yamada KM, Baum BJ. The growth and morphological behavior of salivary epithelial cells on matrix protein coated biodegradable substrata. Tissue Eng 2000; 6: 209-216.

23) Yang XB, Roach HI, Clarke NM, Howdle SM, Quirk R, Shakesheff KM, Oreffo RO. Human osteoprogenitor growth and differentiation on synthetic biodegradable structures after surface modification. Bone 2001; 29: 523-531.

24) Forest PO, Karoum R, Gagnieu CH. Influence of gradual introduction of hydrpphobic groups(stearic acid) in denatured atelocollagen on fibroblasts behavior in vitro. J Biomed Mater Res A 2006; 80: 758-767.

25) Tiller JC, Bonner G, Pan LC, Klibanov AM. Improving biomaterial properties of collagen films by chemical modification. Biotechnol Bioeng 2001; 73: 246-252.

26) Qui Q, Sayer M, Kawaja M, Shen X, Davies JE. Attachment, morphology, and protein expression of rat marrow stromal cells cultured on charged substrate surfaces. J Biomed Mater Res 1998; 42: 117-127.

27) Ohya Y, Matsunami H, Yamabe E, Ouchi T. Cell attachment and growth onfilms prepared from poly(depsipeptide-colactide) having various functional groups. J Biomed Mater Res 2003; 65: 79-88.

28) Jacobson BS, Ryan US. Growth of endothelial and HeLa cells on a new multipurpose microcarrier that is positive, negative, or collagen coated. Tissue Cell 1982; 14: 68-83. 